4. Zeng W, Chen R, Wang X, Zhang Q, Deng W. Prevalence of mental health problems among medical students in China: A meta-analysis. Medicine (Baltimore). 2019 May;98(18):e15337. doi: 10.1097/MD.0000000000015337. PMID: 31045774; PMCID: PMC6504335.

5. Kerr-Gaffney J, Harrison A, Tchanturia K. Social anxiety in the eating disorders: a systematic review and meta-analysis. Psychol Med. 2018 Nov;48(15):2477-2491. doi: 10.1017/S0033291718000752. Epub 2018 Apr 10. PMID: 29631640.

6. Shiryaev O.U. Relationship between family and personal perfectionism of students: gender aspects / O.U. Shiryaev, M.V. Larskikh // Proceedings Of Voronezh State University. Series: Problems Of Higher Education. 2016. - № 2. - P. 12-15.

7. Krasnova V.V. Holmogorova A.B. Social anxiety and its connection with emotional inadaptation, stress level and interpersonal relationships quality in students // Voprosy Psychologii. - 2011. №3. - P. 49-58.

8. Esaulenko I.E. Preventing psychotraumatic stress disorders, adaptation disorder and suicide in young people / I.E. Esaulenko, E.A. Semyonova // System analysis and management in biomedical systems. 2014.-T. 13. No. 2. - P. 453-462.

\title{
Mamontova A. \\ Markers of skin aging and quality of life indicators for women with menopausal syndrome
}

State Budgetary Health Instution "Regional Clinical Hospital No 3", Ministry of Health of the Russian Federation (Russia, Chelyabinsk)

doi: $10.18411 /$ scienceconf-03-2021-13

idsp: scienceconf-03-2021-13

Introduction. Despite the fact that all organs and systems are involved in the aging process, the most significant for women are the visual manifestations of aging, primarily skin changes, in particular the facial skin. This fact is confirmed by the high popularity of cosmetology services. On the one hand, it is known that various skin diseases negatively affect the quality of life (QOL) of a person [1,2].It has been established that QOL worsens if the patient has diseases that are manifested by skin defects [3]. On the other hand, aging of the body and associated changes are the main factor that leads to a decrease in QOL.

Aim.The aim of this study is to identify the relationship between markers of skin aging and QOL in women with menopausal syndrome (MS).

Materials and methods. We examined 36 women in the period of menopausal transition (MT) $(n=12)$ and postmenopause $(\mathrm{PM})(\mathrm{n}=24)$, who applied for a specialized appointment on the problems of menopause in clinics of Regional Clinical Hospital No 3 and Regional Clinical Hospital No 1.

All women underwent anamnesis collection and determination of the modified menopausal index (MMI) (Kupperman H. et al. 1959, modified by Uvarova E.V. 1983) [4].

After the initial examination by a gynecologist, the patients with MS were referred to a cosmetologist who performed computer mapping of the facial skin (CMFS), using a digital video camera "AramoSG" with the skinXPpro program. Facial skin examination included: tests for moisture and elasticity, oiliness (in the T- and U-zones of the face), determination of smoothness / roughness (skin relief), pore sizes, pigmentation, skin sensitivity and test of wrinkle depth and width. Patients were also asked to fill out a special Women's Health Questionnaire (WHQ) [5,6] (by Dr. Myra Hunter, Department of Psychology Adamson, Center ST Thomas Hospital, Lambeth Palace Road, London, UK), which psychometric properties in Russian-speaking population was studied by Russian authors [7]. The questionnaire consists of 37 questions, which are combined into 9 scales [5,6,7]: Depression (DEP), Somatic symptoms (SOM), Memory / concentration (MEM), Vasomotor symptoms (VAS), Anxiety / fears (ANX), Sexual problems (SEX), Sleep (SLE), Menstrual symptoms (MEN), Attractiveness (ATT). Each scale has a dimension from 0 to 1 point, the closer the value is to 0 , the better the QOL of the respondent [7]. Statistical processing was performed 
using the SPSSv.13.0 program. Correlation links between CMFS indicators and WHQ questionnaire scales were considered statistically significant at $\mathrm{p} \leq 0.05$.

Results. The average age of the examined women was $53.5 \pm 5.9$ years. When examining women, it was found that MMI was 24.5 points, which corresponded to a mild degree of MS. Analysis of the face skin condition according to the CMFS data is given in Table 1. The moisture level corresponded to normal, but to the lower limit of normal values. The elasticity test scores were 50 conventional units and were lower than the standard value for this age group, and the oilinessscores in both the $\mathrm{T}$ and U-zones were low. Skin relief indicators were below standard values. The pore sizes were significantly higher than the standard age indices, and the pigmentation level was within the recommended values. The test for the width and depth of wrinkles was also consistent with the normal results for this age group.

Table 1

Indicators of computer mapping of skin in women during the menopausal transition and postmenopause

\begin{tabular}{|l|c|c|c|}
\hline Indicators of CMFS (cu) & Number of women (N) & Me (LQ; UQ) & Normal value(Me) \\
\hline Moisture & 36 & $32(31 ; 35)$ & $30,0-44,9 \mathrm{cu}$ \\
\hline Elasticity & 36 & $50(40 ; 65)$ & $60 \mathrm{cu}$ \\
\hline Oiliness in U-zone & 30 & $0(0 ; 0)$ & - \\
\hline Oiliness in T-zone & 36 & $15(1,5 ; 61)$ & - \\
\hline Roughness & 36 & $25(22,5: 29)$ & $63 \mathrm{cu}$ \\
\hline Pores & 36 & $56(45 ; 75)$ & $48 \mathrm{cu}$ \\
\hline Pigmentation & 36 & $23(11,5 ; 36,5)$ & $54 \mathrm{cu}$ \\
\hline Wrinkles & 36 & $30(16,5 ; 42,5)$ & $35 \mathrm{cu}$ \\
\hline
\end{tabular}

When analyzing QOL indicators according to the WHQ questionnaire, the following data were obtained (Table 2). QOL indicators on the DEP, ANX scales were quite high.The median of these indicators approached zero. According to the MEN and ATT scales, the median was 0.5, which can be regarded as a slight decrease in QOL. For the rest of the scales, QOL was low, with the worst QOL indicator observed when assessing the VAS scale, the median of this indicator was 1 .

Table 2

Indicators of $Q O L$ according to the $W H Q$ questionnaire in patients with climacteric syndrome

\begin{tabular}{|l|c|c|}
\hline \multicolumn{1}{|c|}{ Scales of WHQ } & Number of women (N) & Me (LQ; UQ) \\
\hline Depression & 36 & $0,29(0,14 ; 0,42)$ \\
\hline Somatic symptoms & 36 & $0,72(0,42 ; 0,85)$ \\
\hline Memory / concentration & 36 & $0,67(0,33 ; 1)$ \\
\hline Vasomotor symptoms & 36 & $1(0,5 ; 1)$ \\
\hline Anxiety / fears & 36 & $0,25(0 ; 0,75)$ \\
\hline Sexual problems & 36 & $0,67(0,33 ; 0,67)$ \\
\hline Sleep & 36 & $0,66(0,17 ; 0,67)$ \\
\hline Menstrual symptoms & 36 & $0,5(0,25 ; 0,75)$ \\
\hline Attractiveness & 36 & $0,5(0 ; 1)$ \\
\hline
\end{tabular}

Then the Spearmen correlation analysis of the CMFS data patients with the scales of WHQ questionnaire was carried out.

Moisture test. The correlation analysis of moisture indicators and scales of the WHQ questionnaire revealed the following correlations: moderate negative with the SOM scales ( $p$ 
$=0.034, \mathrm{r}=-0.35)$ and MEM $(\mathrm{p}=0.053, \mathrm{r}=-0.32)$, ANX $(\mathrm{p}=0.029 \mathrm{r}=-0.36)$ and with a SLE scale $(p=0.059 \mathrm{r}=-0.31)$, however, the latter was not statistically significant.

Oiliness test. The oiliness in the U-zone had negative correlations of moderate strength with the MEM $(p=0.035 r=-0.39)$ and VAS $(p=0.013, r=-0.45)$ scales. And the level of oiliness in the T-zone had a similar correlation in strength and direction with the MEM scale $(\mathrm{p}=0.025 \mathrm{r}=-0.36)$.

Pore sizes. The pore sizes had a moderate negative correlation with the VAS scale $(\mathrm{p}=$ $0.010, r=-0.41)$ and similar with the ANX scale $(\mathrm{p}=0.036 \mathrm{r}=-0.34)$.

Pigmentation. The level of skin pigmentation had a positive correlation of moderate strength with the VAS scale $(\mathrm{p}=0.028 \mathrm{r}=0.36)$.

Skin relief and wrinkle width and depth test, elasticity test. There were no statistically significant correlations between the parameters of skin relief / severity of wrinkles and the scales of the WHQ questionnaire. However, a negative correlation of moderate strength was established between the level of skin elasticity and the MEN scale $(p=0.052, r=-0.32)$. It is impossible to unequivocally assess this relationship, since the analysis was carried out for patients in the period of menopausal transition and in postmenopause together.

Conclusion. Thus such markers of skin condition of women with MS as moisture, pore size, oily skin in the T- and U-zones and the level of pigmentation are associated with some QOL indicators of patients.

It was found that the higher moisture and oiliness level of the facial skin in both the $T$ and U-zones, conform the higher QOL indicators of patients with MS. The increase in the pore size of the facial skin of women corresponds to their higher QOL.

In contrast an increase in skin pigmentation corresponds to a lower QOL, namely an increase in the values of the VAS scale of the special WHQ questionnaire.

The study revealed, that moisture, pore size, skin oiliness in the T-zone and pigmentation are associated with the QOL level to a greater extent than the skin relief. Thus the indicators of the condition of the facial skin of women with MS were associated to a greater extent according to the WHQ questionnaire with the MEM and VAS scales.

It should be emphasized that the condition of the skin of patients with MS is associated with their QOL level and is a marker of the aging processes of the entire female body.

$$
* * *
$$

1. Francisco, A. Tausk, Smidt, A.C. et al. Effects of Skin Disease on Quality of Life // NEIM Journal Wach.-2010 Nov. - URL: https://www.jwatch.org/jd201011190000003/2010/11/19/effects-skin-diseasequality-life (available at: 25.02.2021).

2. de Korte, J., Sprangers, M.A., Mombers, F.M. et al. Quality of life in patients with psoriasis: a systematic literature review // J Investig Dermatol Symp Proc.-2004 Mar.-№9(2).-P. 140-7. doi: 10.1046/j.10870024.2003.09110.x. PMID: 15083781.

3. Ribeiro, F., Steiner, D. Quality of life before and after cosmetic procedures on the face: A cross-sectional study in a public service // J CosmetDermatol.-2018 Oct.-№17(5).-P. 688-692. doi: 10.1111/jocd.12723. Epub 2018 Aug 13. PMID: 30105787.

4. Smetnik, V.P. Meditsina klimakteriya [Medicine menopause]. - Yaroslavl': Izd-vo Litera, 2006, 848 p.

5. Kanadys, K., Wiktor-Stoma, A., Lewicka, M. et al. Predictors of the quality of life of women in perimenopausal period // Annals of Agricultural and Environmental Medicine.-2016-23(4).-P. 641-648. doi:10.5604/12321966.1226860.

6. Katainen, Riina. Climacteric-related symptoms in midlife and beyond - studies using the women's health questionnaire // TurunYliopistonJulkaisuja - Annales Universitatis TurkuensisSarja. Ser. D Osa - Tom. 1394. Medica - Odontologica.-2018 Oct. - URL: https://nfog.org/wp-content/uploads/2019/02/thesis.pdf (available at: 25.02 .2021$)$.

7. Bryuhina, E.V., Ivanova, O.V., Usol'ceva, E.N. Psihometricheskie svojstva russkoyazychnoj versii oprosnika zhenskogo zdorov'ya [Women'shealthquestionnaire (WHQ)] // Vestnik YuUrGU. Seriya «Obrazovanie. Zdravoohranenie. Fizicheskaya kul'tura».-2012-№42(301).-P. 134-142. - URL: https://cyberleninka.ru/article/n/psihometricheskie-svoystva-russkoyazychnoy-versii-oprosnika-zhenskogozdorovya-women-s-health-questionnaire-whq (available at: 18.02.2021). 